\title{
Study on cyclic water injection of offshore weak volatile reservoir considering hysteresis effect
}

\author{
Jianting Huang*, Jintao Wu, Guangming Pan, Hao Li and Peng Shi \\ Tianjin Branch of China National Offshore Oil Corporation (CNOOC) Ltd., Tianjin, China. \\ Received 30 July, 2020; Accepted 16 February, 2021
}

\begin{abstract}
Based on the theoretical analysis of capillary hysteresis and relative permeability hysteresis and reservoir numerical simulation, a water injection strategy study was conducted for an offshore weak volatile oil fields after long-term depletion development. The results show that if the capillary hysteresis and relative permeability hysteresis are not considered, the recovery prediction results of the subsequent water injection development will be too small and large, respectively, which is inconsistent with the actual situation. Compared with conventional water injection, cyclic water injection can increase the recovery rate by $1.1 \%$. Its oil displacement presents the characteristics of "three zones and two bands" along the direction from injection to production with water enrichment zone, water stagnation and oil drainage band, oil enrichment zone, oil stagnation and gas drainage band and secondary gas generation zone, respectively. To reduce the influence of the secondary gas cap, the water injection strategy after long-term depletion development includes two slugs of enhanced water injection and cyclic water injection. The timing to turn from enhanced water injection to cyclic water injection is when the formation pressure recovers to bubble point pressure. The optimal half-period of the cyclic water injection phase is 2 months. After the oilfield changed from depletion development to water injection development, the decline rate was improved from 20.8 to $-12.7 \%$. The double-slug water injection strategy considering the hysteresis effect can improve the recovery factor by $18.3 \%$, and provide a practical basis for the efficient development of weak volatile reservoirs.
\end{abstract}

Key words: Capillary force hysteresis, relative permeability hysteresis, weak volatile reservoir, cyclic water injection, water injection strategy.

\section{INTRODUCTION}

Weak volatile oil reservoir is characterized by volatility and shrinkage and its development features are different from that of conventional black oil (Huang et al., 2012; Lin et al., 2017; Shen et al., 2017). QX oilfield is the first weakly volatile oil reservoir in Bohai Bay, which has the characteristics of high dissolved gas oil ratio, high volume coefficient and low pressure difference between formation and saturation pressure. Depletion development was adopted with the initial oil production rate of $4.2 \%$. After 7 years of depletion development, the formation pressure

*Corresponding author. E-mail: huangjt@cnooc.com.cn

Author(s) agree that this article remain permanently open access under the terms of the Creative Commons Attribution License 4.0 International License 
was reduced from 30.5 to $15.5 \mathrm{MPa}$ and the oil production rate decreased to $1.1 \%$, which cannot meet the demand of high-speed development of offshore oil fields (Zhang et al., 2015; Xu et al., 2017; Huo et al., 2016). According to the characteristics of weak volatile oil reservoirs and the long-term depletion development process of QX oilfield, it is necessary to find a suitable water injection development mode for this kind of oilfield. Previous studies have shown that water flooding in late stage after depletion development can significantly improve the development effect of such oilfield (Liu et al., 2009). Compared with conventional water injection, cyclic water injection has more advantages in improving the development effect of conventional oil fields (Gu et al., 2015; Zhang et al., 2003; Yu et al., 2015). In the cyclic water injection development, the capillary displacement and suction process alternate and the high and low permeability layers periodically carry out fluid exchange, thus improving the development effect, which is an important oil increasing mechanism of cyclic water injection (Yu and Zhang, 1993, 1994; Lei et al., 2010). However, the effect of cyclic water injection in different geological reservoir characteristics is obviously different (Fang et al., 2017), among which capillary force is an important factor affecting the effect of cyclic water injection. However, due to the influence of wetting hysteresis and pore geometry, capillary force hysteresis and phase permeability curve hysteresis are common (Lu and Liu, 2015; Yang and Tang, 2014). Therefore, it is necessary to carry out the cyclic water injection research considering the hysteresis effect for this kind of weak volatile oil reservoir, so as to provide reference for similar oilfield development.

\section{MECHANISM OF HYSTERESIS EFFECT}

\section{Depletion development characteristics of QX oilfield}

In the initial stage of production, the depletion development was adopted, and the characteristics of depletion development included: (1) the initial production capacity was high. The viscosity of the crude oil was only $0.35 \mathrm{MPa} \cdot \mathrm{s}$ and the average production capacity of a single well was $200 \mathrm{~m}^{3} / \mathrm{d}$. The oil recovery rate in the initial stage of the oilfield was as high as $4.2 \%$. (2) The formation pressure dropt rapidly. The edge and bottom water body of QX oilfield was small and the volume coefficient of underground crude oil was high. The formation pressure decreased at a decline rate of $10.8 \%$. After 7 years development, the formation pressure decreased from 30.5 to $15.0 \mathrm{MPa}$. (3) Serious degassing of formation oil happened. Due to the rapid decline of formation pressure and the ground saturation pressure difference is only 1.6 MPa, gas dissolved from the crude oil in the formation in the second year of development. In the fourth year, the average gas oil ratio of well production was as high as $751 \mathrm{~m}^{3} / \mathrm{m}^{3}$ and that of wells locating at high portion of the structure was $3300 \mathrm{~m}^{3} / \mathrm{m}^{3}$. (4) Production rate was declining rapidly. After 7 years of development, the oil recovery rate decreased to $1.1 \%$, while the recovery degree was only $16.0 \%$.

\section{Hysteresis effects on water injection}

The development effect of oilfield can be significantly improved by water injection after initial depletion development. The hysteresis effect is significant to the subsequent water injection, especially the cyclic water injection. Hysteresis effect mainly includes capillary force hysteresis and relative permeability hysteresis (Qin and Li, 2003) (Figure 1). Capillary force hysteresis means that the capillary force curve corresponding to the displacement process $(A B)$ cannot completely coincide with the curve corresponding to the imbibition process (BC) (Jiang et al., 2013). Relative permeability hysteresis means that the end point of oil residual oil saturation corresponding to the imbibition process (A1B1) is higher than that of the displacement process (B1C1) (Yang et al., 2009). Whether the hysteresis effect is considered in the numerical simulation have a direct impact on the prediction for the cyclic water injection. In the shutdown stage of cyclic water injection, the displacement curve of capillary force will control the redistribution of oil-water field and play the role of water stagnation and oil drainage. In the injection stage, the reservoir elastic energy plays an oil displacement role by the redistribution of the formation pressure redistribution (Yuan et al., 2015). If relative permeability hysteresis is not considered, curve $\mathrm{BC}$ will be used in the simulation calculation. Compared with the actual running curve $\mathrm{B} 1 \mathrm{C} 1$, the end point of the residual oil saturation will shift to right and the final recovery factor will be larger. If the capillary force hysteresis is not considered, the effect of the capillary force control on the water stagnation and oil drainage will not be reflected, which will lead to the low degree of production in the low permeability area and the final recovery factor will be smaller. Therefore, the influence of hysteresis effects on the distribution of oil-water saturation field should be considered in the prediction of cyclic water injection.

\section{WATER INJECTION STRATEGY CONSIDERING HYSTERESIS EFFECTS}

\section{Establishment of numerical model}

QX oilfield is a fan delta front deposit. The buried depth of the reservoir is $3000 \mathrm{~m}$ and the original formation pressure is $30.5 \mathrm{MPa}$. The pressure difference between formation and saturation pressure is relatively small as the saturation pressure is $28.9 \mathrm{MPa}$. The average porosity is $20 \%$, the average permeability is $150 \times 10^{-3} \mu \mathrm{m}^{2}$ and the viscosity of the formation crude oil is $0.35 \mathrm{MPa}$.s. The volume coefficient of crude oil is 1.780 and the dissolved 


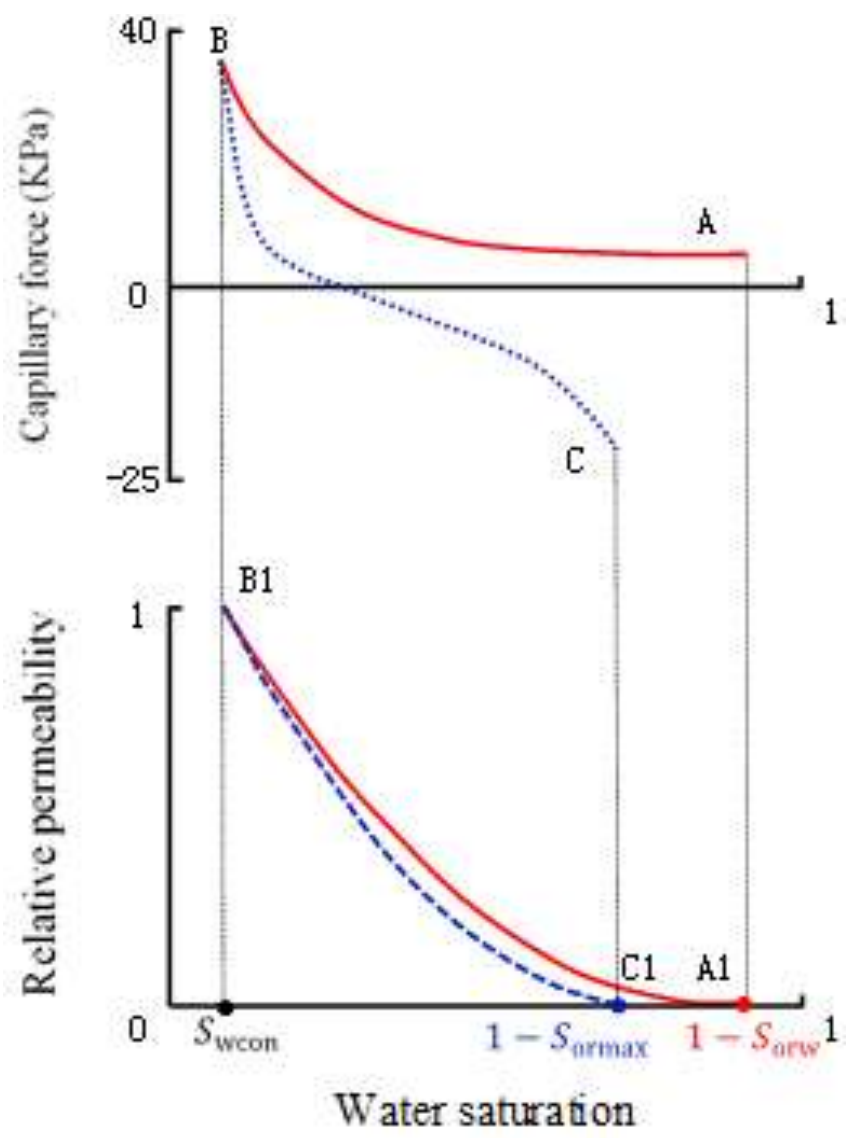

Figure 1. Schematic diagram of hysteresis effects.

gas oil ratio of crude oil is $221 \mathrm{~m}^{3} / \mathrm{m}^{3}$. Crude oil component analysis results show that the content of intermediate hydrocarbon is significantly higher than that of conventional black oil, but it is close to and slightly lower than that of volatile oil. Light component and heavy component are between conventional black oil and volatile oil, which belong to typical weak volatile crude oil (Figure 2).

Based on the QX oilfield reservoir parameters, mechanism reservoir model with a one-injection-oneproduction well pattern and positive rhythm was established. A numerical simulation study considering the influence of hysteresis was carried out using the commercial software CMG's IMEX module. The relative permeability curve and capillary force curve used in the model are shown in Table 1. The actual depletion development process of the oil field is simulated and the subsequent development effects of conventional water injection and cyclic water injection are compared. The half-period of cyclic water injection is 1 month, the fixed liquid production rate is adopted as the daily liquid production rate of a single well is $100 \mathrm{~m}^{3} / \mathrm{d}$, and the injection-production ratio is $1: 1$. The cumulative water injection volume in one water injection cycle is equal to that of conventional water injection and the simulation time is same. The research results show that for weakly volatile oil reservoirs developed after long-term depletion, the final recovery of conventional water injection and cyclic water injection are 35.4 and $36.5 \%$, respectively. Compared with conventional water injection, cyclic water injection can improve oil recovery by $1.1 \%$. As cyclic water injection only changes the working state of water injection well according to certain rules in contrast to conventional water injection, it hardly increases investment and brings economic benefits.

\section{Characteristics of "three zones and two bands" between injection and production wells}

Enhanced oil saturation refers to the difference of remaining oil saturation under different development modes at the same development time. Through the enhanced oil saturation, the description of enhanced oil locations in different EOR methods can be realized (Hou et al., 2013; Pan et al., 2017). The enhanced oil saturation of cyclic water injection compared to conventional water injection is shown in Figure 3.

It can be seen from Figure $3 a$ that the enhanced oil saturation of cyclic water injection compared to conventional water injection is characterized by obvious zoning between injection and production wells. Weak volatile reservoir has the characteristics of high dissolved gas oil ratio, high volume coefficient and low ground saturation pressure difference. Therefore, after depletion development, the formation pressure drops significantly. When the local formation pressure is lower than the saturation pressure, the formation degases seriously. Affected by the density difference, the released dissolved gas will form a secondary gas cap in the high part of the reservoir. Therefore, the zone close to the production well is defined as the secondary gas cap zone (Zone C). The viscosity of underground crude oil in QX oilfield is lower than that of water phase. From the perspective of oil-water mobility ratio, a stable displacement front will be formed during water injection development. Therefore, a water enrichment zone (Zone A) will be formed around the water injection well. Between Zones $A$ and $C$, the remaining oil will be enriched, which is defined as the oil enrichment zone (Zone B). There is a "spindle" shaped enhanced oil band between Zones $A$ and $B$. The range of enhanced oil saturation is 0.00 to 0.32 and the enhanced oil saturation in this zone is positive, which represents the remaining oil that can be produced more by cyclic water injection than by conventional water injection. In the half period of stopping injection during cyclic water injection, capillary force controls the redistribution of oil-water field and oil flows from low permeability layer to high permeability layer. In the half period of reinjection, this 


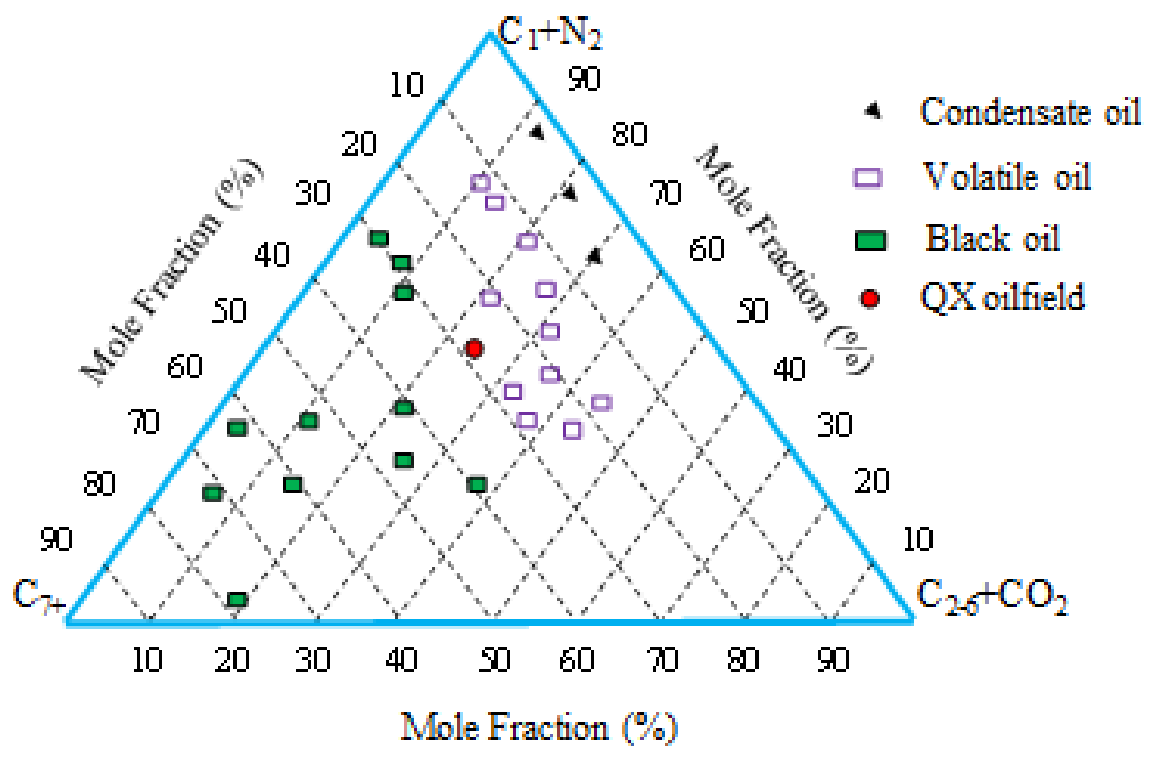

Figure 2. Ternary facies diagram of oil and gas reservoir types.

Table 1. Relative permeability curve and capillary force curve used in the simulation model considering hysteresis effects.

\begin{tabular}{ccccc}
\hline $\begin{array}{c}\text { Water } \\
\text { saturation }\end{array}$ & $\begin{array}{c}\text { Water relative } \\
\text { permeability }\end{array}$ & $\begin{array}{c}\text { Oil relative } \\
\text { permeability }\end{array}$ & $\begin{array}{c}\text { Capillary force of the } \\
\text { displacement process (KPa) }\end{array}$ & $\begin{array}{c}\text { Capillary force of the } \\
\text { imbibition process (KPa) }\end{array}$ \\
\hline 0.34 & 0.00 & 1.000 & 41.60 & 41.60 \\
0.42 & 0.02 & 0.414 & 19.80 & 4.20 \\
0.47 & 0.03 & 0.244 & 15.00 & 0.00 \\
0.51 & 0.04 & 0.133 & 11.20 & -3.00 \\
0.60 & 0.06 & 0.027 & 9.00 & -7.00 \\
0.64 & 0.07 & 0.009 & 7.60 & -10.00 \\
0.68 & 0.08 & 0.002 & 6.40 & -13.00 \\
0.77 & 0.17 & 0.000 & 5.00 & -13.00 \\
\hline
\end{tabular}

part oil is recovered from high permeability channel. Therefore, this "spindle" band is defined as water stagnation and oil drainage band (Band D) and it distributes near the front edge of water drive. There is also a "spindle" shaped enhanced oil band between Zones B and $C$. The range of enhanced oil saturation is -0.18 to 0.00 , which represents the residual oil produced less by cyclic water injection than conventional water injection. In the half period of reinjection, the crude oil in Zone B is displaced into Zone $\mathrm{C}$ as the gas elasticity in the secondary gas cap is large. In the half period of stopping injection, this part of remaining oil cannot be fully discharged because it is far from the high permeability channel, and a blue "spindle" shaped enhanced oil band is formed between Zones $B$ and $C$, which is defined as the oil stagnation and gas drainage band (Band $\mathrm{E}$ ). It can be seen from Figure $3 b$ that Band $D$ is distributed in a ring along the water injection well and the Band $E$ is distributed in a ring around the production well.

In summary, compared with conventional water injection, the enhanced oil in cyclic water injection development shows the characteristics of "three zones and two bands" between injection and production wells. Along the direction from injection to production, water enrichment zone, water stagnation and oil drainage band, oil enrichment zone, oil stagnation and gas drainage band and secondary gas generation zone are developed, respectively. From the perspective of enhancement efficiency, the positive efficiency of water stagnation and oil drainage band (Band $\mathrm{D}$ ) is better than the negative efficiency of oil stagnation and gas drainage band (Band E). Therefore, cyclic water injection can improve oil recovery compared with conventional water injection. However, for the weak volatile reservoir with long-term depletion development, the secondary gas cap is close to the production wells, which makes it difficult to play the 


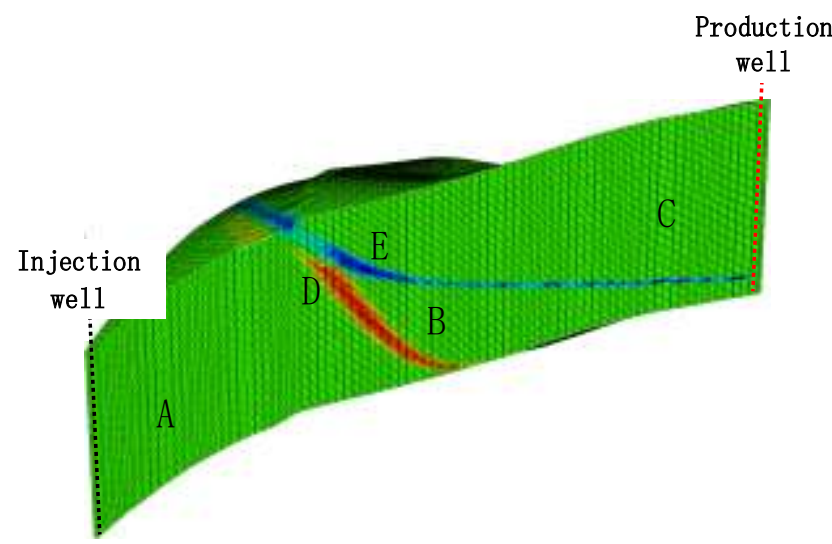

a Vertical section

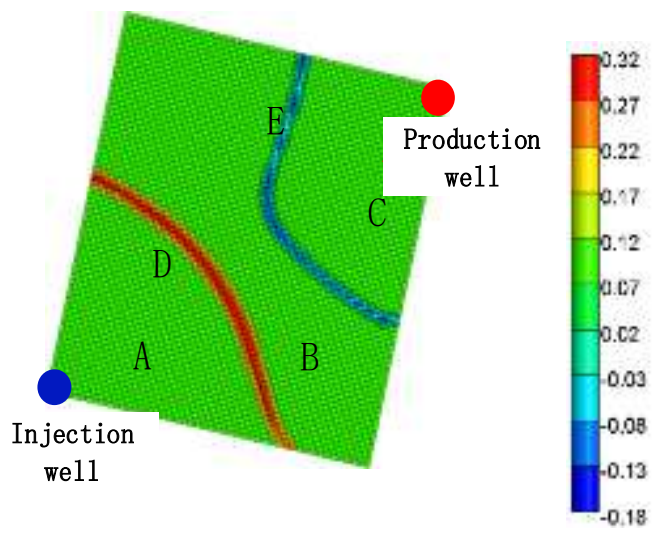

b Horizontal section

Figure 3. Enhanced oil saturation of cyclic water injection compared with conventional water injection considering hysteresis effects.

Table 2. Timing of turning enhanced water injection to cyclic water injection.

\begin{tabular}{clc}
\hline No. & Scheme description & Recovery factor (\%) \\
\hline 1 & Under formation pressure at the end of depletion development $(15.0 \mathrm{MPa})$ & 36.5 \\
2 & Under formation pressure recovered to $85 \%(26.0 \mathrm{MPa})$ & 37.8 \\
3 & Under formation pressure recovered to $90 \%(27.6 \mathrm{MPa})$ & 38.1 \\
4 & Under formation pressure recovered to $95 \%(28.9 \mathrm{MPa})$ & 38.4 \\
5 & Under formation pressure recovered to $100 \%(30.5 \mathrm{MPa})$ & 37.9 \\
\hline
\end{tabular}

role of elastic displacement through the change of injection energy during the reinjection half period of cyclic water injection and is unfavorable to enhance oil recovery. Therefore, it is necessary to reduce the impact of secondary gas cap through the optimization of subsequent water injection strategy, so as to further improve the water injection effect.

\section{WATER INJECTION STRATEGY OF DOUBLE STAGES}

In consideration of the long-term depletion development, before the cyclic water injection, the enhanced water injection should be used to quickly recover the formation pressure, reduce the influence of secondary gas cap on the development and increase the contact range between production well and oil accumulation area. Therefore, the follow-up water injection can be divided into two stages: enhanced water injection and cyclic water injection. In the stage of enhanced water injection, it is necessary to recover the formation pressure quickly by a higher injection-production ratio. Based on the maximum injection capacity of injection wells and liquid production capacity of production wells in QX oilfield, injection is conducted according to the maximum injection-production ratio of $3: 1$ in the enhanced water injection stage. In the cyclic water injection stage, the stopping injection period is equal with the reinjection period. The half period is 2 month and the injection-production ratio of 1:1. The timing of turning the enhanced water injection into cyclic water injection is optimized as shown in Table 2.

Scheme 1 is to directly convert to cyclic water injection after 7 years of depletion development (formation pressure is $15.0 \mathrm{MPa}$ ). Schemes 2 to 5 are to restore formation pressure to corresponding level through enhanced water injection. Scheme 4 is to restore formation pressure to bubble point pressure to cyclic water injection and scheme 5 is to restore formation pressure to original formation pressure. The results show that scheme 4 has highest recovery factor. This is because by enhanced water injection, the formation pressure is restored to the saturation pressure and the viscosity of formation crude oil is minimum and effectively weakens the influence of secondary gas cap on production wells. Therefore, scheme 4 is recommended.

The half period duration is an important factor affecting the effect of cyclic water injection (Liang et al., 1999). On the basis of the study on the duration of cyclic water injection, five schemes with half period duration of $1,2,3$, 4 and 5 months are designed, respectively in the cyclic 


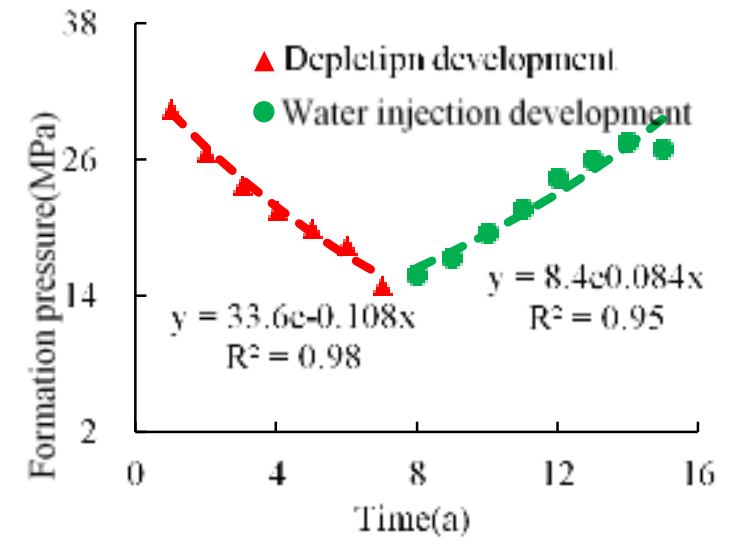

a Formation pressure

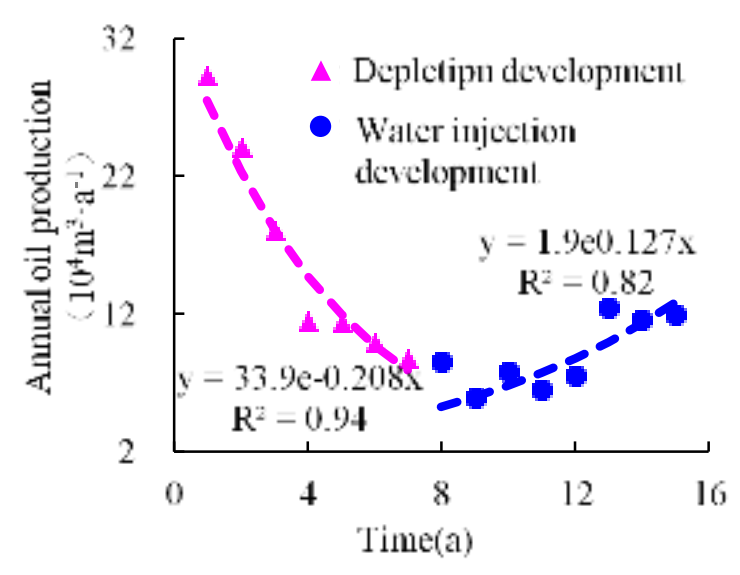

b Oil production

Figure 4. Formation pressure and annual oil production change curve of QX oilfield.

water injection stage. The recovery factors are $38.4,38.9$, $37.8,37.2$ and $36.6 \%$, respectively. The results show that it is better to use equal duration in the two half period (stopping injection period and reinjection period) and half period of 2 months. If the half period is too short, the formation pressure difference is small and the recovery rate is low. If the half period is too long, the formation pressure drops greatly in the stopping injection period, which leads to the large degassing radius around production wells.

In conclusion, compared with conventional water injection, cyclic water injection can improve oil recovery factor by $1.1 \%$. Based on the hysteresis effects analysis, the dual stages water injection strategy can reduce the impact of secondary gas cap on development and increase oil recovery factor to $38.9 \%$.

\section{DEVELOPMENT EFFECT OF WATER INJECTION}

Under the guidance of the established dual stages water injection strategy for the weak volatile oil reservoir, the practice from depletion development to water injection was carried out by the way of convert, the high water cut production wells to injection wells at the reservoir edge. In order to effectively reduce the influence of interlayer interference, three development layer series are divided to ensure the effect of water injection. Two wells with high water cut in the low part of the structure are converted to injection wells to form a well pattern of two injectors and six producers. The average water injecting strength in $\mathrm{QX}$ reservoir is $30 \mathrm{~m}^{3} /(\mathrm{d} \cdot \mathrm{m})$ and the average water injectivity index is $55 \mathrm{~m}^{3} /(\mathrm{d} \cdot \mathrm{MPa})$. The water injection capacity of such oilfield can meet the water injection demand in the stage of double stages. The injection-production ratio is designed as 3:1 in the stage of enhanced water injection and $1: 1$ in the stage of cyclic water injection. Figure 4 shows formation pressure and annual oil production curve after water injection development in QX oilfield. It can be seen that in the first seven years of depletion development, the formation pressure decreases at an annual decline rate of $10.8 \%$. After water injection development, the formation pressure increases significantly with an annual increase rate of $8.4 \%$. The phenomenon of degassing has been obviously controlled and the production gas oil ratio has been reduced from $551 \mathrm{~m}^{3} / \mathrm{m}^{3}$ in the depletion development stage to $202 \mathrm{~m}^{3} / \mathrm{m}^{3}$ in the water injection stage, indicating that the formation pressure has been effectively restored in the enhanced water injection stage and the influence of secondary gas cap on production has been reduced. The decline rate of oil production has reduced from $20.8 \%$ in depletion development stage to $-12.7 \%$ in water injection stage, which means that the oil production increased from natural decline to increase due to stimulation effect. The results of oil recovery prediction by the decline method show that the recovery factor of this kind of weak volatile oil reservoir is only $18.0 \%$ through depletion development, while it can reach $36.3 \%$ and the enhanced recovery can reach $18.3 \%$ through double stages water injection development.

\section{CONCLUSIONS}

(1) If the hysteresis of relative permeability and capillary force are not taken into account, the predicted recovery results of water injection development will be larger and smaller, respectively. Therefore, the hysteresis effects are significant for the formulation of water injection strategy in weak volatile reservoir.

(2) Compared with conventional water injection, cyclic water injection has the characteristics of "three zones and two bands" between injection and production wells. From the perspective of enhancement efficiency, the positive efficiency of water stagnation and oil drainage band is better than the negative efficiency of oil stagnation and 
gas drainage band. Therefore, cyclic water injection can still improve oil recovery by $1.1 \%$ compared with conventional water injection.

(3) The water injection strategy for weak volatile oil reservoir after long-term depletion development includes two stages: enhanced water injection and cyclic water injection. The time for enhanced water injection to turn into cyclic water injection is when the formation pressure recovers to the bubble point pressure and it is better to use equal duration in the two half period (stopping injection period and reinjection period) and half period of 2 months.

(4) The decline rate of oil production in QX oilfield has been decreased from $20.8 \%$ in the depletion stage to $-12.7 \%$ in the water injection stage. The double stages water injection strategy established by considering the hysteresis effects is effective to improve the recovery rate of the weak volatile oil reservoir.

\section{CONFLICT OF INTERESTS}

The authors have not declared any conflict of interests.

\section{REFERENCES}

Fang N, Jiang GH, Li YP, Cheng Q, Zheng H (2017). Development characteristics and potential tapping direction of buried-hill fractured oil reservoirs. Special Oil and Gas Reservoirs 24(3):90-94.

Gu J, Zhong Z, Zhang W, Zhang YG, Huang YS (2015). Displacement mechanism of oil column remaining oil on hydrophilic porous media. Journal of Northeast Petroleum University 39(5):96-100.

Hou J, Pan GM, Lu XJ, Wei CH, Qiu MX (2013). The distribution characteristics of additional extracted oil displaced by surfactantpolymer flooding and its genetic mechanisms. Journal of Petroleum Science and Engineering 112(3):322-334.

Huang WF, Qin XJ, Du XY (2012). Study on development effectiveness of water injection and gas injection for reservoirs with low volatile black oil. Petroleum Geology and Recovery Efficiency 19(4):87-89.

Huo CS, Shi YD, Lin YL (2016). Effects of subsea gas pipeline leakage on adjacent offshore platform. Oil and Gas Storage and Transportation 35(9):1005-1013.

Jiang RZ, Wei XH, Wang SC (2013). Numerical simulation study on cyclic water flooding mechanism considering capillary hysteresis. Petroleum Geology and Recovery Efficiency 20(4):49-52.

Lei DS, Du ZM, Fu Y, Zhang Y (2010). The research of mechanism of imbibition process in cyclic water injection. Journal of Southwest Petroleum University (Science and Technology Edition) 32(1):101-104.

Liang WF, Wu XH, Sun XJ (1999). Using cyclic waterflooding to improve development in late stage of high water cut of lamadian oil field. Petroleum Geology and Oilfield Deuelopment In Daqing 18(5):23-24.

Lin XY, Wei MS, Feng Y, Li L, Han Y (2017). Key moments for hydrocarbon accumulation in Shaximiao Formation on the eastern slope of West Sichuan Depression, Sichuan Basin. Petroleum Geology and Experiment 39(1):50-57.

Liu RG, Wang WM, Su JC (2009). Study on late water flooding in Qikou 18-1 Field. Lithologic Reservoirs 21(1):116-119.

Lu T, Liu ZC (2015). Analysis on influential factors of nitrogen huff and puff effect in fracture- vug type reservoir. Special Oil and Gas Reservoirs 22(6):114-117.
Pan GM, Wu JT, Zhang CQ, Li H, Liu D (2017). Oil enhancement analysis of weak-gel-assisted soak in offshore heavy oil reservoir. Special Oil and Gas Reservoirs 24(6):134-138.

Qin JS, Li AF (2003). Reservoir Physics. Publication: Petroleum University Press pp. 265-269.

Shen BJ, Qin JZ, Feng D, Tao GL, Yang YF, Tenger, Pan AY (2017). Dynamic assessment of organic carbon content and hydrocarbon generation and expulsion efficiency in source rocks. Petroleum Geology and Experiment 39(4):505-510.

Xu T, Hou DJ, Zhao ZB (2017). Controlling factors for the development of high-quality source rocks in Yellow River mouth east sag of Bohai bay basin. Journal of Northeast Petroleum University 41(1):11-20.

Yang $Y$, Tang $L$ (2014). A new method to determine the relative permeability curve parameters by capillary pressure data. Journal of Chongqing University of Science and Technology (Natural Sciences Edition) 16(3):40-43.

Yang YZ, Shen PP, Song XM, Hu YL, Yang SY (2009). Greenhouse gas geo-sequestration mechanism and capacity evaluation in aquifer. Journal of Jilin University (Earth Science Edition) 39(4):744-748.

Yu Di, Huo Fengcai, Zhang Wen, Hu SB, Sun LJ (2015). Estimation of the regional impact on multi-injectors and multi-producers of water-flooded reservoirs. Journal of Northeast Petroleum University 39(2):102-107.

Yu QT, Zhang SF (1993). A preliminary report of the numerical reservoir simulation study for the cyclic flooding. Petroleum Expoloration and Development 6:46-53.

Yu QT, Zhang SF (1994). A second report on the study for the cyclic flooding by numerical reservoir simulation. Petroleum Exploration and Development 2:56-61.

Yuan DY, Hou JR, Song ZJ, Luo M, Zheng ZY, Qu M (2015). Optimization of water injection methods and $\mathrm{N}_{2}$ flooding for EOR in Tahe fractured-vuggy carbonate reservoir. Journal of Northeast Petroleum University 39(6):102-110.

Zhang HG, Guan DY, Su W, Liu PB, Zhang C, Ma XG (2015). Oil and gas enrichment characteristic of compound flower structure: Taking Penglai C structure of Bohai Sea for example. Journal of Northeast Petroleum University 39(4):38-44.

Zhang JC, Bai SZ, Zhang YJ (2003). Cyclic water flooding experiments and research on mechanism of enhancing oil productio. Acta Petrolei Sinica 24(2):76-80. 